\title{
IAA Distribution in Etiolated Spears of Asparagus
}

\author{
Kiyohide Kojima and Naoki Sakurai ${ }^{2}$ \\ Department of Environmental Science, Faculty of Integrated Arts and Sciences, \\ Hiroshima University, Higashi-Hiroshima City 724, Japan
}

Additional index words. Asparagus officinalis, indole-3-acetic acid

Asparagus (Asparagus officinalis L.) spears can grow extraordinarily quickly (Kojima et al., 1993a). Elucidation of a mechanism involved in the ability of asparagus spears to grow so quickly may afford a clue for the improvement of cultivations, not only in asparagus, but also in other products. Kojima et al. (1993a) reported that growing spears had a declining gradient of abscisic acid (ABA) concentration from the tip toward the butt and suggested that ABA was involved in mobilizing carbohydrate reserves for spear growth. However, Patrick and Steains ( 1987) reported that indole-3-acetic acid (IAA) also had a role in promoting assimilate translocation. IAA has been considered to promote cell elongation (Goldsmith, 1977). Thus, IAA may also influence spear growth rate. Green 'Jersey Giant' asparagus spears had higher levels of IAA than white asparagus (Makus and Guinn, 1992). However, to our knowledge, no one has reported IAA distribution in asparagus spears.

In Mar. 1990, 1-year-old crowns of 'Mary Washington 500W' were planted $2 \mathrm{~cm}$ deep in a sandy loam soil in 2-liter pots and placed in a greenhouse at the Hiroshima Prefectural Agricultural Experimental Station (Hara, Japan). In Jan. 1991, the 2-year-old crowns sprouted in a dark room at 20 to $23 \mathrm{C}$. Spears sprouted and grown in darkness can be regarded as being similar to white asparagus. Samples were collected from the following spear height ranges (in millimeters): $35-50$, 51-100, 101-150, 151-200, and 300-400. When spear heights ranged from 35 to $50 \mathrm{~mm}$, six spears were collected. When heights were $>50 \mathrm{~mm}, 12$ spears were collected. Sampled spears were cut into four sections. The tip region consisted of 0 to 15 - and 15 -to $35-\mathrm{mm}$ segments. Spears $>50 \mathrm{~mm}$ long (measured from the tip) were cut below the tip region into two additional lengths in a $1: 2$ ratio and

Received for publication 22 Oct. 1993. Accepted for publication 7 Jan. 1994. We thank the late S. Kuraishi for invaluable suggestions and $\mathrm{T}$. Itou for supplying asparagus spears. The cost of publishing this paper was defrayed in part by the payment of page charges. Under postal regulations, this paper therefore must be hereby marked advertisement solely to indicate this fact.

'To whom reprint requests should be addressed. Current address: Kuchinotsu Branch, Fruit Tree Research Station, Ministry of Agriculture, Forestry, and Fisheries, Kuchinotsu, Nagasaki 859-25, Japan. ${ }^{2}$ Research Plant Physiologist and Professor. designated as middle and butt, respectively. Dissected sections were weighed, immersed immediately in $80 \%$ ethanol, and stored at $-80 \mathrm{C}$ until analysis.

IAA was extracted in the same manner used by Kojima et al. (1993b), and it was determined with a high-performance liquid chromatography system (HPLC) (Shimadzu Co., Kyoto, Japan) equipped with a fluorometric detector according to Akiyama et al.'s (1983) method. Of the fresh-weight sample, $\approx 5 \mathrm{~g}$ was used for extraction. The column for HPLC was an octadecylsilane type and eluent was $25 \% \mathrm{CH}_{3} \mathrm{CN}$ solution ( $2 \mathrm{O} \mathrm{mm}$ acetic acid). The endogenous IAA content was calculated from the ratio of the peak area of IAA to that of indolepropionic acid, which had been added to the extraction as an internal standard.

The spatial distribution of IAA along the spear axis showed a declining gradient from the 0 to $15-\mathrm{mm}$ to the butt regions, regardless of spear length sampled (Table 1). IAA gradients also have been reported in bean (Phaseolus vulgaris L.) stem (Bialek et al., 1983) and pea (Pisum sativum L.) stem (Law and Davies, 1990). The tip of asparagus spears comprises actively dividing meristematic cells (Lill et al., 1990); thus, there is a possibility that IAA may promote the accumulation of assimilates in the tip.

In 100-to 150-mm-long spears, IAA concentrations below the 15-- to 35-mm region were lower than those for other spear lengths (Table 1). In 300- to 400-mm-long spears, lateral buds in the 0 to 15 -mm-long region were visible to the naked eye. Possibly, the lower IAA concentrations in 100- to 150mm-long spears are related to physiological changes before the release of apical dominance.

What factors influence the extraordinary growth rate of asparagus spears? Asparagusic acid, which was abundant ingrowing points of young asparagus spears, promotes asparagus seedling growth (Yanagawa, 1978). However, it is likely that other hormones also participated in controlling the rapid growth of spears (Matsubara, 1980). The growing spears had a declining ABA concentration gradient from the tip toward the butt (Kojima et al., 1993a). We found that the growing spears also had a declining gradient of IAA concentration, suggesting that IAA may promote spear elongation. Thus, asparagusic acid, abscisic acid, and IAA (with the highest concentration in etiolated spear tips and the lowest concentration in the butt) may contribute synergistically to the extraordinary growth rate of asparagus spears, although other hormones and unknown substances also may participate.

\section{Literature Cited}

Akiyama, M., N. Sakurai, and S. Kuraishi, 1983. A simplified method for the quantitative determination of indoleacetic acid by high performance liquid chromatography with a fluorometric detector. Plant Cell Physiol. 24:143 1-1439.

Bialek, K., W. Meudt, and J.D. Cohen. 1983. Indole-3-acetic acid (IAA) and IAA conjugates applied to bean stem sections. Plant Physiol. 73:130-134.

Goldsmith, M.H.M. 1977. The polar transport of auxin. Annu, Rev. Plant Physiol. 28:439-478.

Kojima, K., S. Kuraishi, N. Sakurai, T. Itou, and K. Tsurusaki. 1993a. Spatial distribution of abscisic acid and 2-trans-abscisic acid in spears, buds, rhizomes and roots of asparagus (Asparagus officinalis L.). Scientia Hort. 54: 177- 189.

Kojima, K., S. Kuraishi, N. Sakurai, and K. Fusao. 1993b. Distribution of abscisic acid in different parts of the reproductive organs of tomato. Scientia Hort. 56:23-30.

Law, D.M. and P.J. Davies. 1990. Comparative indole-3-acetic acid levels in the slender pea and other pea phenotypes. Plant Physiol. 93:15391543.

Lill, R. E., G.A. King, and E.M. O’Donoghue. 1990. Physiological changes in asparagus spars immediately after harvest. Scientia Hort. 44:191-199.

Makus, D.J. and G. Guinn. 1992. Higher levels of $\mathrm{ABA}$ and IAA are found in green than in white asparagus spears. HortScience 27:1047.

Matsubara, S. 1980. ABA content and levels of GA-like substances in asparagus buds and roots in relation to bud dormancy and growth. J. Amer. Soc. Hort. Sci. 105:527-532.

Patrick, J.W. and K.H. Steains. 1987. Auxin dose-response curves and effects of inhibitors of polar auxin transport. J. Expt. Bet. 38:203-210.

Yanagawa, H. 1978. Structure and physiological properties of asparagusic acid (in Japanese). Kagaku to Seibutsu. 16:124-129.

Table 1. IAA concentration in various sections of etiolated asparagus spears of various lengths.

IAA conen (picomol-g $\left.\mathrm{g}^{-1}\right)^{2}$

\begin{tabular}{lccccc}
\cline { 2 - 6 } & \multicolumn{5}{c}{ Length range of harvested spears (mm) } \\
\cline { 2 - 6 } Section & $<50$ & $50-100$ & $101-150$ & $151-200$ & $300-400$ \\
\hline Tip (mm) & & & & \\
$0-15$ & $240 \pm 8^{y}$ & $1900 \pm 97$ & $1500 \pm 150$ & $2000 \pm 310$ & $1600 \pm 250$ \\
$15-35$ & $220 \pm 8$ & $1600 \pm 70$ & $530 \pm 62$ & $2000 \pm 150$ & $1300 \pm 120$ \\
Middle & $\cdots$ & $960 \pm 65$ & $160 \pm 70$ & $1000 \pm 17$ & $780 \pm 90$ \\
Butt & $\cdots-$ & $210 \pm 34$ & $150 \pm 25$ & $810 \pm 74$ & $180 \pm 9$ \\
\hline
\end{tabular}

${ }^{2}$ Grams of fresh weight.

All values of IAA concentration are means \pm SE of three determinations. 